\title{
A POLÍTICA DE EDUCAÇÃO PROFISSIONAL NO GOVERNO LULA: UM PERCURSO HISTÓRICO CONTROVERTIDO
}

\author{
GaUdênCIO FrigotTo* \\ Maria CiavatTA* \\ Marise Ramos ${ }^{*+*}$
}

\begin{abstract}
RESUMO: Este artigo analisa as políticas de educação profissional do Governo Lula em seu percurso controvertido entre as lutas da sociedade, as propostas de governo e as ações e omissóes no exercício do poder. Partindo-se da revogação do Decreto n. 2.208/97, principal regulamentação da educação profissional no governo anterior, cujo processo expressa a disputa por hegemonia nesse campo, analisa-se a contradição da proposta de lei para a educação profissional, ao invés de retomar o debate sobre a LDB. Posteriormente, analisam-se os programas Escola de Fábrica, Integração da Educação Profissional ao Ensino Médio na Modalidade de Educação de Jovens e Adultos (PROEJA) e Inclusão de Jovens (PROJOVEM). Apesar das declaraçôes favoráveis à integração entre formação básica e formação específica, a política de educação profissional processa-se mediante programas focais e contingentes numa travessia marcada por intensos conflitos e no terreno da contradição.
\end{abstract}

Palavras-chave: Educação profissional. Ensino técnico. Educação integrada. Currículo integrado. Certificação.

* Doutor em Ciências Humanas (Educação), professor titular visitante do Programa de Políticas Públicas e Formação Humana da Universidade do Estado do Rio de Janeiro (UERJ) e membro do Comitê Diretivo do Conselho Latino-americano de Ciências Sociais (ClaCSO). E-mail: gfrigotto@globo.com

** Doutora em Ciências Humanas (Educação), professora titular associada ao Programa de Pósgraduação em Educação da Universidade Federal Fluminense (UFF), coordenadora do GT "Trabalho e Educação" (2002-2004) da Associação de Pesquisa e Pós-Graduação em Educação (ANPED) e pesquisadora sênior apoiada pelo CNPq e FAPERJ. E-mail: mciavatta@terra.com.br

*** Doutora em Ciências Humanas (Educação), professora adjunta da Universidade Estadual do Rio de Janeiro (UerJ) e vice-diretora de Ensino da Escola Politécnica de Saúde Joaquim Venâncio, da Fundação Oswaldo Cruz.E-mail: marise-ramos@uol.com.br

Educ. Soc., Campinas, vol. 26, n. 92, p. 1087-1113, Especial - Out. 2005

Disponível em <http://www.cedes.unicamp.br> 
A política de educação profissional no Governo Lula...

Professional EDUCATION POLICY IN THE LULA'S ADMINISTRATion: A CONTROVERTED HISTORICAL TRAJECTORY

ABSTRACT: This paper analyzes the professional education policies in the Lula's administration. It shows their contradictory historical trajectory mixing social fights, government proposals and actions and omissions in the exercise of power. Beginning from the revocation of Decree 2.208/97, the main regulation of professional education of the previous administration, which reveals the dispute for power in this area, it explores the contradiction of proposing a specific bill for professional education instead of reopening the debate on the LDB (Brazilian Education Basic Tenets Law). It then analyzes such programs as Factory School, Integrated Professional Education for Young and Adult People (PROEJA) and Young People Inclusion (PROJOVEM). Despite declarations favoring the integration of basic education and specific training, the professional education policies are based on focal, contingent programs, marked by intense conflicts and contradictions.

Key words: Professional education. Technical education. Integrated education. Integrated curricula. Certification.

\section{Introdução}

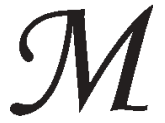

ais uma vez, na história da educação brasileira, com a eleição do presidente Lula da Silva em outubro de 2002, as expectativas de mudanças estruturais na sociedade e na educação, pautadas nos direitos inscritos na Constituição Federal de 1988, não se realizaram. Apesar da produção de conhecimentos sobre contradições, desafios e possibilidades da educação profissional, produzidas especialmente no âmbito da área Trabalho e Educação, ${ }^{1}$ que esperávamos ser apropriada pela política pública do Estado brasileiro, o que se revelou foi um percurso controvertido entre as lutas da sociedade, as propostas de governo e as ações e omissóes no exercício do poder.

$\mathrm{O}$ fato de a regulamentação da educação profissional formulada a partir da LDB (Lei n. 9.394/96), especialmente com o Decreto n. 2.208/ 97 e as Diretrizes Curriculares Nacionais para o ensino técnico e o ensino médio (Brasil, CNE, 1998a, 1998b, 1999a, 1999b), ter sido contestada pelas forças progressistas da sociedade brasileira e assimilada pelos segmentos conservadores, sempre de forma contraditória, não levaria a esperar que a política de democratização e de melhoria da qualidade da 
educação profissional se instituísse a partir da implementação dessas regulamentações. Ao contrário, de 1996 a 2003, lutou-se por sua revogação, apontando-se para a necessidade da construção de novas regulamentações, mais coerentes com a utopia de transformação da realidade da classe trabalhadora brasileira.

Por isso, a problematização sobre a política de educação profissional, que tem como referência a produção de conhecimento na área e as lutas sociais, desafiou-nos a analisar o percurso tomado por essa política no Governo Lula, que representa, na verdade, a disputa entre os setores progressistas e conservadores da sociedade brasileira pela hegemonia nesse campo. Em razão do exposto, neste texto refletimos sobre nossa participação e a de outros estudiosos da área Trabalho e Educação em muitos fóruns de discussão e de polêmica sobre os rumos dados à educação e à certificação profissional, ao ensino médio, ao ensino médio técnico e, mais recentemente, à educação de jovens e adultos (Frigotto et al., 2005a, 2005b; Frigotto, 2005; Ciavatta, 2005; Ramos, 2005; Ferreira \& Garcia, 2005; Costa \& Conceição, 2005; Rodrigues, 2005; Kuenzer, 2003).

$\mathrm{O}$ tratamento a ser dado à educação profissional, anunciado pelo Ministério da Educação ao início do Governo Lula, seria de reconstruí-la como política pública e

corrigir distorçôes de conceitos e de práticas decorrentes de medidas adotadas pelo governo anterior, que de maneira explícita dissociaram a educação profissional da educação básica, aligeiraram a formação técnica em módulos dissociados e estanques, dando um cunho de treinamento superficial à formação profissional e tecnológica de jovens e adultos trabalhadores. (Brasil, MEC, 2005, p. 2)

Entre essas correções, uma das mais relevantes, em razão do seu fundamento político e por se tratar de um compromisso assumido com a sociedade na proposta de governo, foi a revogação do Decreto n. 2.208/ 97, restabelecendo-se a possibilidade de integração curricular dos ensinos médio e técnico, de acordo com o que dispõe o artigo n. 36 da LDB. Por se tratar de um ato do Poder Executivo, a ele foi conferido um caráter de transitoriedade, o que tem justificado a idéia de se propor ao Congresso Nacional um anteprojeto de "Lei da Educação Profissional e Tecnológica" - que, a exemplo da Lei da Reforma Universitária, remonta à fragmentação do sistema educacional realizada pelas leis orgânicas dos anos de 1940. 
A política de educação profissional no Governo Lula...

Não obstante essas declarações favoráveis à integração, a política de educação profissional processa-se mediante programas focais e contingentes, a exemplo dos seguintes: Escola de Fábrica, Integração da Educação Profissional ao Ensino Médio na Modalidade de Educação de Jovens e Adultos (PROEjA) e do Inclusão de Jovens (PROjovem). São essas contradiçōes que nos propomos analisar a seguir, explicitando e problematizando o percurso controvertido das políticas de educação profissional no Governo Lula (janeiro de 2003 a julho de 2005). Esta análise se apóia em dois pressupostos: a) que a mudança da materialidade estrutural da sociedade brasileira, em que o campo educacional é apenas uma particularidade, move-se de forma lenta, como expressão da natureza das relações de poder das classes sociais; b) que a luta por mudanças mais profundas, como conseqüência, efetiva-se numa travessia marcada por intensos conflitos e no terreno da contradição.

A (des)integração da educação básica e profissional: mudanças que conservam

Discutimos em outro artigo (Frigotto et al., 2005b) que a opção por um novo decreto que revogasse o 2.208/97, em vez da simples regulamentação pelo Conselho Nacional de Educação dos artigos 36 e 39 a $42 \mathrm{da}$ LDB, ou de uma lei específica para a educação profissional, teve, entre outras razões, a consciência de que as forças conservadoras ocupariam espaço para fazerem valer seus interesses, tanto no Conselho Nacional de Educação quanto no Congresso.

Um novo decreto seria um dispositivo transitório que, enquanto garantisse a pluralidade de ações asistemas e instituiçôes de ensino, mobilizasse a Sociedade Civil em torno do assunto. O que se pretendia era a (re)construção de princípios e fundamentos da formação dos trabalhadores para uma concepção emancipatória dessa classe. Acreditava-se que a mobilização da sociedade pela defesa do ensino médio unitário e politécnico, a qual conquanto admitisse a profissionalização, integraria em si os princípios da ciência, do trabalho e da cultura, promoveria um fortalecimento das forças progressistas para a disputa por uma transformação mais estrutural da educação brasileira.

Isso, certamente, levaria a uma revisão profunda e orgânica da atual Lei de Diretrizes e Bases da Educação Nacional e não a uma lei espe- 
cífica para a educação profissional. $\mathrm{O}$ fato é que, após um ano de vigência do Decreto n. 5.154/2004, a mobilização esperada não ocorreu. O que se viu, logo a seguir, foi o inverso. De uma política consistente de integração entre educação básica e profissional, articulando-se os sistemas de ensino federal e estaduais, passou-se à fragmentação iniciada internamente, no próprio Ministério da Educação. ${ }^{2}$

Com efeito, a partir de 28 de julho de 2004, três dias após o Decreto n. 5.154/2004 ser exarado, foi anunciado o Programa Escola de Fábrica com um modelo restrito à aprendizagem profissional. Além disso, passou-se a enfrentar uma nova e complicada conjuntura: a reestruturação do MEC colocou a política do ensino médio na Secretaria de Educação Básica, separando-a da política de educação profissional.

Algumas medidas tomadas pelo Ministério da Educação posteriormente comprovaram que a política de integração não seria prioridade e que não estavam claras as concepções das equipes dessas secretarias sobre o tema. Anteriormente à reorganização ministerial, a estratégia pensada para a consolidação da concepção de ensino médio e educação profissional sob os princípios do trabalho, da ciência e da cultura implicava dar alguns passos.

Primeiramente, seria necessário encaminhar ao Conselho Nacional de Educação uma proposta de Diretrizes Operacionais e de revisão das Diretrizes Curriculares Nacionais coerentemente com a nova concepção. Em segundo lugar, o Ministério deveria fomentar a implantação do ensino médio integrado em sua própria rede e nas redes estaduais. Como formulador e coordenador da política nacional, um plano de implementação dessa modalidade previria um acompanhamento com discussão, avaliação e sistematização das experiências a partir do que se reuniriam elementos políticos e pedagógicos, além de força social, que fundamentariam um projeto de revisão da LDB e a necessária proposição de novas Diretrizes Curriculares Nacionais para o ensino médio e a educação profissional, construídas de forma efetivamente democrática e participativa com os educadores.

No caso da rede federal, o Programa de Melhoria e Expansão da Educação Profissional (PROEP) poderia ser utilizado como fonte de financiamento dessa iniciativa, juntamente com o processo de convencimento político, tanto das instâncias dirigentes quanto da comunidade em geral. É certo que, no caso dos dirigentes, tal como se viu durante a discussão 
A política de educação profissional no Governo Lula...

sobre a revogação do Decreto n. 2.208/97, esse convencimento não ocorreria sem desgaste, em razão do movimento de acomodação conservadora à reforma do governo anterior, por eles liderado, conforme demonstram alguns estudos. ${ }^{3}$ Porém, provavelmente, se teria as comunidades das instituições federais como aliadas, uma vez que a luta pela revogação do Decreto n. 2.208/97 partiu especialmente de seus servidores e estudantes.

No caso das redes estaduais, além do PROEP, também o Programa de Melhoria do Ensino Médio (PROMED) poderia redirecionar seus objetivos e prioridades de financiamento. ${ }^{4}$ Com efeito, ainda ao início do ano de 2004, quando o ensino médio e a educação profissional eram geridos conjuntamente pela SEMTEC, um acordo foi discutido com as secretarias estaduais de Educação do Paraná e do Espírito Santo, por proposição destas, tratando do interesse desses sistemas de ensino em implantar o ensino médio integrado com apoio financeiro, político e pedagógico do Ministério da Educação (Ferreira \& Garcia, 2005).

Elaborou-se, então, um projeto de assessoramento a essas secretarias pelo Ministério da Educação, com foco nas áreas de maior complexidade na elaboração da política educacional dos sistemas de ensino e do projeto político-pedagógico das escolas, quais sejam: currículo, formação de professores, identidade e memória escolar. O projeto era composto por objetivos e açóes que contribuiriam para o desenvolvimento de propostas curriculares de ensino médio integrado sob os princípios da ciência, do trabalho e da cultura, contemplando-se a formação continuada de professores e o resgate coletivo da memória e da identidade da escola.

Com esses propósitos, em 17 de agosto de 2004, o ministro da Educação assinou convênios com os secretários de Educação dos Estados do Paraná, do Espírito Santo e de Santa Catarina, prevendo-se o repasse de recursos financeiros para apoiar a implantação do ensino médio integrado nesses estados. Decorrido um ano após esse ato, os convênios não foram efetivados. Paradoxalmente, o MEC anunciou o interesse de mais um conjunto de secretarias estaduais de Educação pela implantação do ensino médio integrado, a partir do que a Secretaria de Educação Básica passou a realizar seminários sobre as diretrizes dessa política nos respectivos estados. $^{5}$

A despeito da complexidade política e pedagógica que caracteriza o tema, o que ocorreu foram discussóes aligeiradas e, por vezes, encaminhamentos para a organização do ensino médio em três séries anuais, se- 
guidas por mais um ano de estudos profissionalizantes. Reiteramos que a sobreposição de disciplinas consideradas de formação geral e de formação específica ao longo de um curso não é o mesmo que integração, assim como não o é a adição de um ano de estudos profissionais a três de ensino médio. A integração exige que a relação entre conhecimentos gerais e específicos seja construída continuamente ao longo da formação, sob os eixos do trabalho, da ciência e da cultura (Ramos, 2005, p. 122).

Nesse contexto, constatamos que a Secretaria de Educação do Paraná possivelmente seja aquela que enfrentou o desafio de construir o ensino médio integrado em escolas de sua rede, por meio de um processo sistemático de elaboração coletiva de princípios e diretrizes ético-políticas e pedagógicas sólidas, garantindo, simultaneamente, as condições objetivas necessárias para sua realização. Entre estas estão os concursos públicos para a ampliação do quadro docente permanente e a melhoria da infra-estrutura física e didática. Apesar do convênio assinado com o MEC, essas medidas têm sido sustentadas exclusivamente por recursos do orçamento estadual.

No que se refere a sua função de coordenar a política nacional, o que lhe confere o dever de propor diretrizes curriculares ao Conselho Nacional de Educação e de agir para conquistar a hegemonia de suas concepções, o MEC declinou de exercê-la com relação à formação integrada, delegando a esse órgão tal prerrogativa. Ocupando esse espaço, o CNE exarou e o ministro da Educação homologou o Parecer n. 39/2004 da Câmara de Educação Básica, do Conselho Nacional de Educação, e a Resolução n. 01/2005, que atualizaram as Diretrizes Curriculares Nacionais vigentes (Brasil, CNE, 1998 e 1999) às disposições do Decreto n. $5.154 / 2004$, contraditoriamente, nos termos adequados à manutenção das concepções que orientaram a reforma realizada no governo anterior por meio do Decreto n. 2.208/97.

Ao solicitar ao CNE, "em caráter de urgência, manifestação da Câmara de Educação Básica, com vistas à adequação das Diretrizes Curriculares Nacionais no que se refere à Educação Profissional Técnica de nível médio [ao Decreto n. 5.154/2004], para orientar os sistemas de ensino e as escolas na imediata implantação do referido Decreto, a partir do próximo ano letivo" (Brasil, CNE, 2004, p. 1, grifo nosso), o MEC ratificou a vigência das respectivas diretrizes, demonstrando concordância com seus princípios e conteúdos, e, de certa forma, reduzindo o conteúdo do Decreto n. 5.154/2004. Reforçou-se, assim, a idéia de que a re- 
A política de educação profissional no Governo Lula...

forma anterior era boa, mas não teria sido bem implementada. Este sinal foi dado também por outros documentos, como aquele que apresenta as orientaçóes curriculares para o ensino médio (Brasil, MEC, 2004, p. 6).

Cabe lembrar que, na disputa pela revogação do Decreto n. 2.208/ 97 por um novo decreto, o sentido do texto que dispunha sobre a necessidade de se observar "os objetivos contidos nas Diretrizes Curriculares Nacionais definidas pelo Conselho Nacional de Educação" (Decreto n. 5.154/2004, inciso I do artigo $4^{\circ}$ ) não estava na manutenção das diretrizes vigentes, mas sim na perspectiva de novas diretrizes que deveriam ser exaradas posteriormente, mediante debate com os sistemas e as instituições de ensino e ampla participação docente.

Tal postura contradiz não só o documento de educação básica e educação técnica e profissional que serviu de base à campanha eleitoral do presidente Lula, mas, sobretudo, as diretrizes e propostas formuladas por educadores no Fórum Nacional de Educação, constituído por 34 instituições científicas e sindicais. De fato, efetiva-se, por esta acomodação, uma cultura, como lembrava Florestan Fernandes, de "modernização do arcaico".

O Parecer n. 39/2004 afirma que, para se implantar a nova forma introduzida por esse decreto, qual seja, a integração do ensino médio com a educação profissional, "é exigida uma nova e atual concepção, que deverá partir do que prescreve o $\$ 2^{\circ}$ do Art. $4^{\circ}$ do referido Decreto" 6 (idem, ibid., p. 5). Ora, se é uma nova e atual concepção político-pedagógica que se exige, não se poderiam manter as mesmas diretrizes definidas para o ensino médio e para a educação profissional técnica vigentes.

A demonstração de que não há qualquer "nova concepção" pedagógica nesse parecer é a compreensão de que a educação profissional técnica de nível médio deva ser oferecida simultaneamente e ao longo do ensino médio. A proposta de integração distingue-se de simultaneidade. Este último princípio está de acordo com aquele que se manifesta permanentemente no parecer: o da independência entre os cursos. Não foi isso que se buscou instituir com o Decreto n. 5.154/2004.

Uma das alterações propostas pelo parecer e incorporada pela Resolução n. $01 / 2005$, no seu primeiro artigo, foi o acréscimo de um parágrafo $3^{\circ}$ ao artigo 12 da Resolução n. 03/98, descrevendo as formas como a educação profissional técnica de nível médio poderá se articular com o ensino médio, sem revogar o parágrafo $2^{\circ} .7 \mathrm{O}$ texto desse parágrafo de- 
termina que a possibilidade de o ensino médio preparar para o exercício de profissóes seja condicionada à independência dos cursos. Na hipótese de não ter sido um descuido do relator, haveria, certamente, o propósito de se manter o princípio da independência dos cursos que se tentou superar com o novo decreto.

Apesar de reconhecer a forma integrada como um curso único, com matrícula e conclusão únicas, o parecer considera que os conteúdos do ensino médio e os da educação profissional de nível técnico são de "naturezas diversas". Re-estabelece-se, assim, internamente ao currículo, uma dicotomia entre as concepçôes educacionais de uma formação para a cidadania e outra para o mundo do trabalho, ou de um tipo de formação para o trabalho intelectual e de outro tipo para o trabalho técnico e profissional Contrariamente a isso, afirmamos que

No currículo que integra formação geral, técnica e política, o estatuto de conhecimento geral de um conceito está no seu enraizamento nas ciências como "leis gerais" que explicam fenômenos. Um conceito específico, por sua vez, configura-se pela apropriação de um conceito geral com finalidades restritas a objetos, problemas ou situações de interesse produtivo. A tecnologia, nesses termos, pode ser compreendida como a ciência apropriada com fins produtivos. Em razão disto, no currículo integrado nenhum conhecimento é só geral, posto que estrutura objetivos de produção, nem somente específico, pois nenhum conceito apropriado produtivamente pode ser formulado ou compreendido desarticuladamente da ciência básica. (Ramos, 2005, p. 120)

A manutenção da validade das Diretrizes Curriculares Nacionais para o Ensino Médio e para a Educação Profissional, após a edição do novo decreto, dá continuidade à política curricular do governo anterior, marcada pela ênfase no individualismo e na formação por competências voltadas para a empregabilidade. Reforça-se, ainda, o viés adequacionista da educação aos princípios neoliberais. Neste particular, reafirma-se um dos fetiches ou uma das vulgatas, insistentemente afirmada nos oito anos de Governo Fernando Henrique Cardoso, de que no Brasil não havia falta de empregos, mas de "empregáveis". O relator, de forma inteligente e competente, por conhecer bem o pensamento do governo passado e dos empresários, acomodou o Decreto n. 5.154/2004 aos interesses conservadores, anulando o potencial que está em sua origem. Sob as Diretrizes Curriculares Nacionais vigentes e um parecer que sedimenta a separação, as perspectivas de mudanças substanciais de ordem conceptual, ética, 
A política de educação profissional no Governo Lula...

política e pedagógica, que poderiam ser impulsionadas pelo governo, ficam cada vez mais afastadas.

O PROEJA: a conquista de um direito restrito pela formação mínima

Um dos princípios norteadores de uma política de educação profissional integrada à educação básica foi a regulamentação dos cursos que, sob a vigência do Decreto n. 2.208/97, foram abrigados sob o denominado "nível básico" da educação profissional. A oferta desses cursos, como parte da política de educação profissional do governo anterior, objetivava atender a demandas por qualificação e requalificação profissional da população adulta de baixa escolaridade por intermédio de uma rede específica de cursos de curta duração, completamente dissociados da educação básica e de um plano de formação continuada. ${ }^{8}$

Enquanto o MEC se ocupava especialmente da educação profissional técnica, sem uma política consistente que atentasse para as demandas sociais dos trabalhadores jovens e adultos que realizam cursos supletivos de nível fundamental, o Ministério do Trabalho e Emprego desenvolveu seu plano de formação sem se preocupar com a recuperação da escolaridade e a organização de itinerários formativos. Setores expressivos da sociedade afirmavam, então, a necessidade de se implementar uma política pública de formação profissional, integrada ao sistema público de emprego e à educação básica.

A qualificação e a requalificação, seja na forma de cursos ou de módulos, deveriam também ser organizadas com o fim de constituir itinerários formativos correspondentes às diferentes especialidades ou ocupaçóes pertencentes aos setores da economia e promover, simultaneamente, a elevação de escolaridade dos trabalhadores. Nessa medida, seria fundamental que esses cursos obtivessem aprovação legal por meio do fornecimento de créditos e certificados escolares reconhecidos pelo MEC e pelo MTE e, dessa forma, fossem vinculados aos processos regulares de ensino e também reconhecidos e considerados pelas empresas em negociações, convenções e contratos coletivos.

Essas preocupações orientaram a formulação das premissas às quais a educação profissional deveria atender, descritas no artigo $2^{\circ}$ do Decreto n. 5.154/2004, a saber: a organização, por áreas profissionais, em função da estrutura socioocupacional e tecnológica; e a articulação de esfor- 
ços das áreas da educação, do trabalho e emprego, e da ciência e tecnologia. Pelo mesmo motivo, o artigo $3^{\circ}$ desse decreto indica a possibilidade de oferta dos cursos e programas de formação inicial e continua$\mathrm{da}^{9}$ de trabalhadores segundo itinerários formativos, compreendidos como o conjunto de etapas que compõem a organização da educação profissional em uma determinada área, possibilitando o aproveitamento contínuo e articulado dos estudos. $\mathrm{O}$ parágrafo $2^{\circ}$ do mesmo artigo indica a necessidade de esses cursos se articularem com a modalidade de educação de jovens e adultos. ${ }^{10}$

Com base nesses preceitos legais, o MEC lançou o Programa de Integração da Educação Profissional ao Ensino Médio na Modalidade de Educação de Jovens e Adultos - PROEJA (Brasil, 2005b), por meio do qual obrigou as instituições da rede federal de educação técnica e tecnológica ${ }^{11}$ a destinar, em 2006, o correspondente a 10\% das vagas oferecidas em 2005 para o ensino médio integrado à educação profissional destinado a jovens acima de 18 anos e adultos que tenham cursado apenas o ensino fundamental. $\mathrm{O}$ porcentual de vagas a ser aplicado nos anos posteriores será definido por ato do MEC. Apresenta-se como objetivo desse programa a ampliação dos espaços públicos da educação profissional para os adultos e uma estratégia que contribui para a universalização da educação básica. $^{12}$

Vale observar que as instituições federais, individualmente, salvo algumas poucas exceçôes, ou como rede, não fizeram qualquer movimento significativo, no sentido de integrar os ensinos médio e técnico. Ademais, com o reconhecimento dos Centros Federais de Educação Tecnológica (CEFETs) como instituições de ensino superior, ${ }^{13}$ a prioridade tenderá a ser conferida à oferta da educação superior em detrimento do nível médio. Diante disso, a instituição do PROEJa pode ter fundamentos mais corporativos do que ético-políticos (Gramsci, 1991), seja para a rede, seja para a Secretaria de Educação Profissional e Tecnológica (SETEC).

Para a SETEC, a oferta da educação profissional integrada ao ensino médio na modalidade EJA manteria uma incumbência residual com a educação básica, da qual ela foi esvaziada quando a responsabilidade pelo ensino médio foi destinada à Secretaria de Educação Básica (SEB) e a educação de jovens e adultos - com a qual a política de educação profissional nunca havia se ocupado - abrigada pela Secretaria de Educação Continuada, Alfabetização e Diversidade (SECAD). ${ }^{14}$ Para a rede federal, essa medida contribui para justificar sua manutenção na esfera político-adminis- 
A política de educação profissional no Governo Lula...

trativa própria e não na esfera da educação superior, na qual sua identidade e diretrizes seriam compartilhadas com as demais instituições de ensino superior.

Quanto aos tipos de oferta, o Decreto n. 5.478/2005, nos artigos $3^{\circ}$ e $4^{\circ}$, prevê que a formação profissional integrada ao ensino médio na modalidade EJA possa ocorrer como formação inicial e continuada ou como habilitação técnica. No primeiro caso, os cursos terão carga horária máxima de 1.600 horas, das quais no mínimo, 1.200 serão destinadas à formação geral e 200 à formação profissional. No segundo caso, os cursos devem ter carga horária máxima de 2.400 horas, das quais 1.200 para formação geral. ${ }^{15}$ A carga horária mínima da formação específica deve atender a estabelecida para a respectiva habilitação.

Observamos algumas incoerências na disposição sobre as cargas horárias que, ao nosso ver, incorrem em deslizes éticos, políticos e pedagógicos. Primeiramente, não há por que defini-las como máximas. A redução da carga horária de cursos na modalidade EJA com relação aos mínimos estabelecidos em lei para a educação regular não deve ser uma imposição, mas sim uma possibilidade. O sentido de tal possibilidade está no pressuposto de que os estudantes da EJA são sujeitos de conhecimento, com experiências educativas formais ou não, que lhes proporcionaram aprendizagens a se constituírem como pontos de partida para novas aprendizagens quando retornam à educação formal.

Limitar a carga horária dos cursos a um "máximo" é, na verdade, admitir que aos jovens e adultos trabalhadores se pode proporcionar uma formação "mínima”. Em contrapartida, se por essa carga horária se distribuem os mínimos definidos para a formação geral e a específica, como se poderia elevar a carga horária de uma sem se diminuir a outra?

Discutimos que um currículo integrado tem o trabalho como princípio educativo no sentido de que este permite, concretamente, a compreensão do significado econômico, social, histórico, político e cultural das Ciências e das Artes e da Tecnologia (Ramos, 2005, p. 108). Um currículo assim concebido baseia-se numa epistemologia que considere a unidade de conhecimentos gerais e conhecimentos específicos e numa metodologia que permita a identificação das especificidades desses conhecimentos quanto à sua historicidade, finalidades e potencialidades. Baseia-se, ainda, numa pedagogia que visa à construção conjunta de conhecimentos gerais e específicos, no sentido de que os primeiros funda- 
mentam os segundos e estes evidenciam o caráter produtivo concreto dos primeiros (idem, ibid., 109). Nessa perspectiva, não procede delimitar o quanto se destina à formação geral e à específica, posto que, na formação em que o trabalho é princípio educativo, estas são indissociáveis e, portanto, não podem ser predeterminadas e recortadas quantitativamente.

Como não poderia deixar de ser, os alunos que concluírem os cursos no âmbito do PROEjA farão jus ao diploma com validade nacional, que confira a habilitação profissional e a conclusão do ensino médio, possibilitando o prosseguimento de estudos em nível superior. Os cursos podem ser estruturados e organizados em etapas com terminalidade, prevendo-se saídas intermediárias e possibilitando ao aluno a obtenção de certificados de conclusão do ensino médio com qualificação para o trabalho, referentes aos módulos cursados, desde que tenha concluído com aproveitamento a parte relativa à formação geral (Decreto n. 5.478/2005, artigo $6^{\circ}$, parágrafo único). As instituições federais poderão aferir e reconhecer, mediante avaliação individual, conhecimentos e habilidades obtidos em processos formativos extra-escolares (idem, artigo 7o).

Tentou-se, dessa maneira, possibilitar a organização de itinerários formativos, bem como a certificação de conhecimentos construídos pelos trabalhadores em processos formativos, sejam esses de caráter formal ou não, coerentemente com as preocupações que levaram à incorporação desses preceitos, como direito, ao Decreto n. 5.154/2004. Não obstante, reaparece a dicotomia entre formação geral e específica, uma vez que se exige a conclusão da parte relativa à formação geral para que se torne possível a certificação da qualificação para o trabalho, referentes aos módulos cursados. Para isso, o curso teria de ser organizado em etapas e cargas horárias distintas de formação geral e de formação específica, inviabilizando a forma integrada.

Tal como ocorre no Parecer n. 39/2004 e na Resolução CNE n. 01/ 2005, na modalidade EJA o princípio que (des)articula formação geral e específica também não é a integração mas sim a independência entre elas. Em síntese, lamentavelmente, como constatamos anteriormente, essas medidas se constituem, na verdade, em falsos avanços; simulacros que nos distraem enquanto permitem a vitória dos conservadores, os quais, no meio de "uma ou outra alteração", mantêm tudo como estava antes.

Outro aspecto que nos preocupa diz respeito às concepções teórico-metodológicas da educação de jovens e adultos com relação às quais 
A política de educação profissional no Governo Lula...

as instituições da rede possuem históricos diferenciados. Sua aproximação com a EJA começou a ocorrer a partir de 1995, quando se ampliou a mobilização da Sociedade Civil pela oferta da EjA e, também, quando se inicia a implementação do PLANFOR pelo Ministério do Trabalho. Nesse contexto, organizações não-governamentais, empresas e sindicatos passaram a oferecer programas de EJA. Esses programas enfrentaram o problema da certificação dos alunos, levando-os a procurarem instituições públicas com autonomia para realizá-la, independentemente dos exames supletivos oferecidos pelos sistemas estaduais de ensino. Em razão da sua natureza jurídica de autarquia, foram predominantemente as Escolas Técnicas Federais e os CEFETs que assumiram essa função.

Algumas dessas instituições aproveitaram a oportunidade para se aproximarem da política de educação de jovens e adultos e para ampliar o atendimento da educação profissional para trabalhadores já inseridos na População Economicamente Ativa (PEA), com recursos do PLANFOR. Outras, aliadas ou não à primeira perspectiva, valeram-se dessa relação para captar recursos das organizações, cobrando pelo acompanhamento pedagógico do projeto e/ou pela aplicação de provas aos estudantes. Em ambos os casos, essa relação provocou contradições no interior das instituiçóes federais, entre elas a resistência de parte de suas comunidades, opondo-se à ampliação de sua função social numa perspectiva mais democrática. A cultura do trabalho simples e da baixa escolaridade dos trabalhadores, que esteve na origem dessas instituições, há muito havia sido superada pela cultura do trabalho complexo, de base científico-tecnológica, e pela relação pedagógica com jovens em idade escolar prevista.

O fato é que as principais experiências e o acúmulo de debates relativos às concepções de EJA se encontram principalmente na Sociedade Civil. Em razão disso, no ano de 2003, a então SEMTEC desenvolveu um estudo quantitativo e qualitativo sobre a oferta de EJA articulada à educação profissional, que contou com a participação de pesquisadores de universidades envolvidos com o tema. Pretendia-se retratar, para o ministério, as realizações da Sociedade Civil organizada nesse campo, destacando-se seus êxitos, problemas e necessidades. Esperava-se, a partir de referências teórico-metodológicas e elementos de realidade, contribuir para a formulação, pelo governo, de uma proposta educacional adequada às necessidades dos estudantes trabalhadores. Caberia verificar em que medida esse estudo foi apropriado pela política pública como referência para o aprofundamento conceitual no âmbito dos sistemas de ensino. 
A hegemonia das políticas compensatórias: os programas Escola de Fábrica e PROJOVEM

Entre as distorçôes que a política de educação profissional do atual governo pretendia corrigir estava, além da revogação do Decreto n. 2.208/97, o redirecionamento dos recursos do PROEP para os segmentos públicos. De fato, no início do ano de 2004, o MEC anunciou a reativação de projetos anteriormente apresentados, iniciada pela destinação de $\mathrm{R} \$$ 8 milhôes a mais para o segmento estadual do que para o comunitário. ${ }^{16}$ Não obstante, é nesse mesmo período que se vê divulgada a política da parceria público-privado do governo federal, com ressonância na política de educação profissional. Anuncia-se então um novo programa de educação profissional usando o modelo de parceria público-privado. ${ }^{17}$ Esse projeto envolveria a União, o "Terceiro Setor" (Montaño, 2002) e a iniciativa privada na oferta de formação técnica de jovens em cursos de qualificação profissional. A idéia é baseada no projeto Formare, da Fundação Iochpe, ${ }^{18}$ iniciado com recursos do PROEP, e se apóia nas parcerias firmadas com empresas e indústrias de todo o país para que elas façam a qualificação profissional de jovens. Esse programa, implementado a partir de 2005, foi designado como "Escola de Fábrica".

O Programa Escola de Fábrica (Brasil, 2005a) objetiva dar a formação profissional inicial a jovens entre 16 e 24 anos, matriculados na educação básica (ensino fundamental, médio, educação de jovens e adultos, Brasil Alfabetizado), cujas famílias tenham renda per capita de até um salário mínimo. O investimento de R \$ 25 milhões é oriundo do PROEP e está voltado para a criação de 560 escolas em 2005, organizadas por unidades gestoras, como ONGs, instituições públicas e outras. Essas organizaçōes implantam unidades de ensino nas empresas, elaboram o programa curricular, fornecem a orientação técnico-pedagógica e certificam os alunos. A certificação pode ficar também a encargo dos CEFETs.

As empresas são responsáveis por infra-estrutura física, funcionários e técnicos que atuam como instrutores, além dos custos da implantação das unidades formadoras. Asseguram também alimentação, uniforme e transporte aos alunos. O MEC financia a bolsa aos alunos, no valor de $\mathrm{R} \$ 150,00$. As unidades formadoras têm capacidade para 20 alunos por ano, mantendo cursos com duração mínima de 600 horas. ${ }^{19}$

O Programa Escola de Fábrica é definido como um programa de inclusão social, voltado para beneficiar estudantes excluídos do mercado 
A política de educação profissional no Governo Lula...

de trabalho, e que pretende estimular empresas privadas a praticarem a responsabilidade social. Paralelamente a essa política tem-se, ainda, o Programa Nacional de Inclusão de Jovens - Projovem (Brasil, 2005), implantado pela Secretaria-Geral da Presidência da República em parceria com o Ministério da Educação, o Ministério do Trabalho e Emprego e o Ministério do Desenvolvimento Social e Combate à Fome. Seus destinatários são jovens de 18 a 24 anos, que terminaram a quarta série, mas não concluíram a oitava série do ensino fundamental e não têm vínculos formais de trabalho.

A finalidade do PROJOVEM é proporcionar formação ao jovem, por meio de uma associação entre a elevação da escolaridade, tendo em vista a conclusão do ensino fundamental, a qualificação com certificação de formação inicial e o desenvolvimento de açóes comunitárias de interesse público. Argumenta-se que o Programa pretende contribuir especificamente para a re-inserção do jovem na escola; a identificação de oportunidades de trabalho e capacitação dos jovens para o mundo do trabalho; a identificação, elaboração de planos e o desenvolvimento de experiências de açôes comunitárias; a inclusão digital como instrumento de inserção produtiva e de comunicação. Um projeto político-pedagógico com diretrizes e orientaçóes proporciona aos jovens um curso de 5 horas diárias, por um período de 12 meses, totalizando 1.600 horas. ${ }^{20}$ Aos alunos matriculados é concedida uma bolsa no valor de R \$ 100,00.

Sendo ambos os programas dirigidos aos desempregados ou aos alunos de escolas públicas, com vistas à inserção profissional, o que os caracteriza é a falta de integração com outras políticas como a de inserção profissional e de melhoria da renda das famílias. Destacamos que políticas de inserção profissional não abrangem somente a preparação profissional. Outras duas dimensões são imprescindíveis, conforme descrevem Laflamme \& Baby (1993).

Segundo esses autores, a preparação profissional remete aos conhecimentos transmitidos aos jovens nos órgãos de formação - legitimados por um diploma ou certificado - com vistas a habilitá-los a conseguir um lugar no mercado de trabalho. Essa etapa seria cumprida pela educação básica e profissional. A transição profissional, por sua vez, seria caracterizada pela procura de emprego e por um conjunto de mecanismos associados que se situam na interface da escola e do trabalho (centros de emprego, programas de auxílio ao emprego, entre outros). 
Em seguida, vem a fase da integração profissional propriamente dita, que pode ocorrer na forma de uma relativa estabilidade, de marginalização e/ou de convivência com o trabalho precário. A natureza, a importância e o grau de coincidência dessas três dimensões dependeriam de aspectos macrossociais e macroeconômicos e de outros aspectos, tais como as políticas de emprego e de transição escola-empresa.

Cabe, ainda, nomear uma questão de fundo que tem sido recorrentemente apontada nos documentos de avaliação dos programas, pois se trata de um pressuposto à sua formulação, devendo, portanto, envolver amplo debate social. A questão é: deve-se retardar a entrada dos adolescentes e jovens no mercado de trabalho - e com isso dar prioridade à sua sociabilidade, educação e formação profissional, reservando ainda os escassos empregos para os adultos - ou facilitar a inserção profissional de adolescentes de baixa renda a partir dos 16 anos, propiciando-lhes condiçôes de gerar renda para suas famílias e para sua permanência na escola? ${ }^{21}$

Embora definamos como prioridade política a primeira - a elevação da escolaridade e o combate ao trabalho precoce -, é preciso, ao mesmo tempo, providenciar para que as várias situações relacionadas às condições de trabalho e de formação sejam consideradas nas formulações de políticas públicas.

$\mathrm{Na}$ delimitação do universo de jovens, pode-se encontrar diferentes particularidades. Ainda que o maior número de jovens filhos de trabalhadores resida em bairros populares ou em favelas das médias e grandes cidades do Brasil, deve-se reconhecer que uma outra quantidade trabalha com a família em minifúndios ou como arrendatários ou assalariados do campo. Outros, ainda, vivem em acampamentos e assentamentos do Movimento dos Trabalhadores Rurais Sem Terra (Frigotto, 2004, p. 181).

Todos esses jovens, mesmo com suas especificidades, tendem a sofrer um processo de amadurecimento precoce, inserindo-se no mercado formal ou "informal" de trabalho. Essa necessidade leva à imprescindibilidade de políticas públicas que enfrentem o plano conjuntural e emergencial, atentando para a particularidade e a diversidade dos grupos de jovens inseridos precocemente no mundo do trabalho. Ao mesmo tempo, entretanto, as políticas devem encaminhar mudanças ou reformas estruturais no sentido da superação da desigualdade social e da universalização efetiva da educação básica (fundamental e média). 
A política de educação profissional no Governo Lula...

Concordamos com Márcio Pochmann quando este indica a necessidade de políticas distributivas e emancipatórias. No primeiro caso, o preceito fundamental é a garantia, pelo Estado, de uma renda mínima que leve o jovem a retornar à escola, tendo, para isso, uma fonte de renda que compense o que ganharia trabalhando de forma precária. Associado a isso, na perspectiva emancipatória, está o resgate do papel da educação e da formação, postergando-se o ingresso dos jovens no mercado de trabalho e permitindo colocar à disposição de todos as condições isonômicas de competição pelos postos de trabalho existentes e vagas de geração de trabalho e renda (Pochmann, 2004, p. 226).

Ambos os programas, com diferenças na sua finalidade e organização, resgatam um preceito que pretendíamos ter superado desde a revogação da Lei n. 5.692/71, qual seja, tomar a qualificação profissional como política compensatória à ausência do direito de uma educação básica sólida e de qualidade. Esta deve ser garantida em qualquer idade, integrada à possibilidade de habilitação profissional mediante a qual se constituam identidades necessárias ao enfrentamento das relações de trabalho excludentes.

No caso específico do Escola de Fábrica, ao depender da parceria empresarial para sua realização, além do uso do fundo público pelas organizações privadas, tende a predominar o viés assistencialista. No fundo, essa política retoma o fundamento que esteve na origem da educação profissional no início do século passado: formar mão-de-obra necessária ao desenvolvimento econômico e educar psicofisicamente os jovens trabalhadores para a divisão social do trabalho.

\section{Considerações finais: a história se repete?}

Não podemos deixar de ter a História como referência quando buscamos elaborar estas consideraçôes finais, decorrentes da análise crítica que buscamos desenvolver sobre a política de educação profissional nos primeiros dois anos e meio do Governo Lula. O controvertido percurso entre as propostas de governo anunciadas ao povo brasileiro durante a campanha de 2002 e as ações e omissões no exercício do poder revelam alguns saldos de boas intenções e estratégias que se tornam obstáculos ao avanço da efetiva democratização da educação nesse período de governo.

Devemos perguntar em que bases o projeto de desenvolvimento econômico e social do Brasil de hoje supera ou se acomoda à lógica da 
divisão internacional do trabalho que, historicamente, reduz os trabalhadores a fatores de produção e, em razão disso, torna sua formação um investimento em "capital humano", psicofísica e socialmente adequado à reprodução ampliada do capital. Em que medida o projeto nacional democrático popular não se dissolveu pela inserção subordinada do Brasil na economia internacional globalizada e, dessa forma, justificam-se as políticas de educação profissional baseadas nas teses do man power aproach?

Tratamos de três grandes questôes, todas polêmicas e interdependentes pelo que representam para uma população tradicionalmente excluída dos benefícios sociais. Um primeiro ponto é a oferta de uma formação mínima, por intermédio do PROEJA, aos setores tradicionalmente excluídos da educação regular. $\mathrm{O}$ atendimento às demandas por qualificação por parte de uma população jovem e adulta de baixa escolaridade deu-se por uma rede de cursos de curta duração, dissociados da educação básica e de uma política de formação continuada durante o Governo Cardoso, por meio do PlANFOR, sob a ação do Ministério do Trabalho e Emprego.

O atual governo lançou o PROEJA, sob a ação do MEC, a ser desenvolvido pela rede federal de educação técnica e tecnológica, os CEFETs, destinando $10 \%$ das vagas oferecidas em 2005 para o ensino médio integrado à educação profissional para jovens acima de 18 anos e adultos que tenham cursado o ensino fundamental. No entanto, esses cursos terão uma carga horária de educação geral e profissionalizante sensivelmente diferente da carga horária dos cursos regulares da rede. Note-se ainda que, neste momento, o interesse principal da rede volta-se para acumular recursos intelectuais, organizacionais e financeiros para se tornarem, efetivamente, instituições de ensino superior. Prevê-se que o PROEJA seja uma ação residual para o MEC e para os CEFETs.

Outro ponto controverso de que tratamos diz respeito aos Programas Escola de Fábrica e PROJOVEM. Entre as distorções das políticas educacionais, que o atual governo pretendia corrigir, estava a revogação do Decreto n. 2.208/97 e o redirecionamento do PROEP dos setores privados e comunitários para os segmentos públicos. Enquanto se discutia o novo decreto que tomou forma no Decreto n. 5.154 em julho de 2004 e que veio permitir a integração do ensino médio com a educação profissional, anuncia-se um novo programa de educação profissional, o Programa Escola de Fábrica, utilizando o modelo de parceria público-privado, iniciado com recursos do PROEP e em parceria com empresas e indústrias de 
A política de educação profissional no Governo Lula...

todo o país. Em resumo, pelo novo decreto restabelece-se a possibilidade do ensino integrado entre educação geral e formação específica; e pelo novo programa, salvo outros rumos que possa tomar, coloca-se sob a tutela da lógica empresarial a formação dos jovens excluídos do mercado de trabalho e que não tiveram acesso à educação regular.

Voltado para a mesma faixa da população, também mediante a concessão de bolsas, o PROJOVEM busca integrar ensino fundamental, qualificação profissional e ação comunitária. $\mathrm{O}$ que caracteriza ambos os programas é a falta de integração com outras políticas, tais como a inserção profissional e a melhoria de renda das famílias. O que somente poderia ocorrer por meio de um projeto de desenvolvimento econômico e social e de distribuição de renda.

Há, também, um sentido geral conservador nas mudanças pela (des)integração da educação básica e profissional. Acreditávamos que a transitoriedade do Decreto n. 5.154/2004 não seria superada somente no plano jurídico, mas na luta social. Quase que paralelamente ao novo decreto, dissociaram-se, no interior do MEC, as secretarias de ensino médio e de educação profissional e começou-se a discutir a elaboração de uma lei orgânica para a educação profissional, associada a programas focais destinados a jovens e adultos trabalhadores. Em seus fundamentos, argumenta-se que se pretende analisar e interpretar alguns artigos da LDB e também sistematizar e integrar as redes existentes de educação profissional e tecnológica no âmbito de um sistema nacional de educação, configurando-se a educação profissional e tecnológica como um subsistema.

Enuncia-se, ainda, a intenção de integrar a política educacional e a política de geração de emprego e renda. A organização do referido subsistema implicaria o ordenamento dos elementos que já integram o universo amplo de educação profissional e tecnológica no âmbito de uma “política pública estratégica e de Estado” (Brasil, MEC, 2005).

Voltando ao processo de discussão e luta por uma LDB, dos anos de 1980 aos meados dos de 1990, travadas por políticos e intelectuais, muitos dos quais apoiaram e/ou compóem este governo, fazemos os seguintes questionamentos: a) por que fazer uma lei específica para analisar e interpretar alguns artigos de LDB e não levar adiante um novo embate em torno da LDB, que a modifique ou que a ela incorpore o que foi perdido quando da aprovação da Lei n. $9.394 / 96$ e do Decreto n. 2.208/ 
97? b) Por que o MEC abdica de organizar o Sistema Nacional de Educação, constituindo um (sub)sistema para uma modalidade educacional, com regulamentação própria, nos moldes das leis orgânicas do ensino da década de 1940? c) Qual o sentido do Fórum Nacional de Educação Profissional que se articula em torno da elaboração dessa lei, e a que armadilhas estaremos submetidos, dada a sua ocupação e a hegemonia exercida pelos segmentos privados?

De forma semelhante ao que ocorreu em 1942, o governo conduz-se para o terreno das reformas parciais, antes que para uma reforma integral que, neste momento, equivaleria à reapropriação da Lei de Diretrizes e Bases da Educação Nacional na perspectiva defendida nos anos de 1980, cujo princípio básico era o direito à educação laica, gratuita, de qualidade, politécnica e de formação omnilateral. Não há como não se perceber um paralelo entre a organização do ensino nas reformas de 1942 e o Programa Escola de Fábrica, por exemplo. Naquele momento, o ensino industrial das "escolas de aprendizagem" foi organizado pela Lei Orgânica do Ensino Industrial. ${ }^{22}$ A preocupação do governo era engajar as indústrias na qualificação de seu pessoal, além de obrigá-las a colaborar com a sociedade na educação de seus membros. "Esse fato decorreu da impossibilidade de o sistema de ensino oferecer a educação profissional de que carecia a indústria e da impossibilidade de o Estado alocar recursos para equipá-lo adequadamente" (Romanelli, 1997, p. 155).

Não obstante toda a expectativa em contrário, a vitória das forças conservadoras tem feito predominar a manutenção de princípios e práticas que orientaram as reformas no Governo Fernando Henrique Cardoso. A insistência de alguns setores políticos e intelectuais em explicitar esse fenômeno tenta, pelo menos, manter aceso o debate e abertos os espaços da contradição. Não é possível, entretanto, "re-inventar" a realidade. Reconhecer que o Governo Lula, também nesse campo, não assumiu, se não marginalmente, o projeto discutido com as forças progressistas no período pré-eleitoral é uma necessidade. Buscar compreender as diferentes determinações que conduziram a isso e buscar agir nos diferentes espaços em que atuamos é um imperativo ético-político, pois de uma ou de outra forma estamos implicados neste processo.

Recebido e aprovado em agosto de 2005. 


\section{Notas}

1. O estado da arte sobre políticas educacionais nos anos de 1980 e 1990 integrou a pesquisa coordenada por Frigotto \& Ciavatta (2004). Um dos textos que a integra, de autoria de Ramos (2004), faz uma revisão histórica da legislação educacional sobre o ensino médio e a educação profissional no período.

2. Não é possível, no escopo deste texto, analisar as determinações políticas externas e internas ao MEC, que conduzem a esse paradoxo, cujas conseqüências estamos apontando nesta breve análise.

3. Referimo-nos aqui especialmente à pesquisa coordenada por Frigotto \& Ciavatta (2004). Outros estudos realizados no âmbito de cursos de pós-graduação também chegam a conclusōes semelhantes. Citamos, por exemplo, Cordeiro (2004).

4. O uso de recursos desses programas exigiria uma negociação com o Banco Interamericano de Desenvolvimento (BID), com o qual são contratados. Mas a determinação política do governo brasileiro certamente levaria o acordo a bom termo. Ademais, a iminente finalização dos contratos de empréstimos - sobre os quais vários estudos demonstram desvantagens significativas para a economia e a política brasileiras (Tommasi et al., 1996) - traria a necessidade de se tomar efetivamente essa política como prioridade ao ponto de planejá-la orçamentariamente.

5. Os seminários foram realizados nos seguintes estados: Paraíba, Tocantins, Florianópolis, Espírito Santo, Ceará, Mato Grosso, Acre, Maranhão, Bahia. Os autores deste artigo estiveram presentes em 4 (quatro) deles.

6. Que diz o seguinte: "Na hipótese prevista no inciso I do $\$ 1^{\circ}$, a instituição de ensino deverá, observados o inciso I do art. 24 da Lei n. 9.394, de 1996, e as diretrizes curriculares nacionais para a educação profissional técnica de nível médio, ampliar a carga horária total do curso, a fim de assegurar, simultaneamente, o cumprimento das finalidades estabelecidas para a formação geral e as condições de preparação para o exercício de profissões técnicas".

7. O artigo 12 da Resolução n. 03/98 ficou, então, com a seguinte redação: "Não haverá dissociação entre a formação geral e a preparação básica para o trabalho, nem esta última se confundirá com a formação profissional. $\$ 1^{\circ} \mathrm{A}$ preparação básica para o trabalho deverá estar presente tanto na base nacional comum como na parte diversificada. $\$ 2^{\circ} \mathrm{O}$ ensino médio, atendida a formação geral, incluindo a preparação básica para o trabalho, poderá preparar para o exercício de profissóes técnicas, por articulação com a educação profissional, mantida a independência entre os cursos. $\$ 3^{\circ} \mathrm{A}$ articulação entre a Educação Profissional Técnica de nível médio e o Ensino Médio se dará das seguintes formas: I. integrada, no mesmo estabelecimento de ensino, contando com matrícula única para cada aluno; II. concomitante, no mesmo estabelecimento de ensino ou em instituiçōes de ensino distintas, aproveitando as oportunidades educacionais disponíveis, ou mediante convênio de intercomplementaridade; e III. subseqüente, oferecida somente a quem já tenha concluído o Ensino Médio" (grifo nosso).

8. Esses cursos foram oferecidos no âmbito do Plano de Formação Profissional do Ministério do Trabalho (PLANFOR) ou livremente por instituiçóes públicas e privadas.

9. Algumas análises consideram que essa foi uma nova denominação do "nível básico" da educação profissional, antes definido pelo Decreto n. 2.208/97. A despeito de controvérsias, parece-nos que a formação inicial se refere a cursos que "iniciam" os trabalhadores numa área profissional como uma primeira formação. A formação continuada implica todas as 
experiências formativas após o trabalhador ter adquirido uma primeira formação profissional, tais como atualização, desenvolvimento, aperfeiçoamento, especialização, entre outras - seja na mesma área profissional ou em áreas diversas. A formação inicial, independentemente da escolaridade, somente existe no Brasil porque ainda não se universalizou a educação básica.

10. Uma discussão sobre os itinerários formativos como necessidade e como contradição para a classe trabalhadora encontra-se em Frigotto et al. (2005a).

11. Essa rede do MEC é formada por 144 escolas de educação profissional: 34 são centros federais de educação tecnológica (CEFETS), 43 unidades descentralizadas, 36 escolas agrotécnicas federais (EAF), 30 escolas técnicas vinculadas às universidades federais, e a Escola Técnica Federal de Palmas, em Tocantins.

12. A exposição de motivos que fundamenta o decreto argumenta que, em termos quantitativos, a proposta implicará, em 2006, a abertura de 20 mil vagas e, a partir de 2007, pelo menos mais de 40 mil vagas anuais - sem um único aporte orçamentário além dos recursos já destinados às instituições federais de educação tecnológica.

13. Decreto n. 5.225/2004, que alterou dispositivos do Decreto n. 3.860/2001, o qual dispõe sobre a organização do ensino superior e a avaliação de cursos e instituições.

14. Não sabemos até que ponto a instituição dessa medida foi discutida com a SECAD. Entretanto, arriscamos opinar que a articulação entre as instâncias responsáveis, respectivamente, pela educação profissional, pelo ensino médio e pela educação de jovens e adultos não tem correspondido às necessidades impostas pela implementação de uma política de tamanha relevância e complexidade.

15. Em contraposição, a carga horária prevista para o ensino médio é de 2.400 horas e, para a educação profissional técnica, dependendo da área profissional, tem-se $800,1.000 \mathrm{ou}$ 1.200 horas. A Resolução n. 01/2005, por sua vez, estabeleceu que os cursos de ensino médio integrado à educação profissional técnica tenham, no mínimo, 3.200 horas.

16. As informaçôes constantes desse parágrafo foram obtidas em notícias divulgadas no sítio www.mec.gov.br/semtec, de 18/6/2004. O total de projetos em tramitação no PROEP era de 237, sendo 58 do segmento federal, 87 do segmento estadual e 92 do comunitário. Os projetos do segmento a que nos referimos aqui correspondem a três propostas da Superintendência Estadual de Educação Profissional (suepro) do Rio Grande do Sul, no valor total de aproximadamente $\mathrm{R} \$ 2,88$ milhóes. No segmento comunitário, trata-se de uma proposta da Fundação Esperança, de Santarém, no Pará, no valor de R \$ 2,15 milhões.

17. Notícia divulgada pela Assessoria de Comunicação Social do MEC em abril de 2004.

18. A Fundação Iochpe-Maxon S.A. é um grupo empresarial que opera nos segmentos de autopeças e equipamentos ferroviários. A Fundação desenvolve programas nas áreas de Educação, Cultura e Bem-Estar Social, realizando parcerias com entidades públicas e privadas. Informações obtidas em www.fiochpe.org.br.

19. Esses cursos são compostos por três módulos: um de 120 horas para "reforço escolar do ensino básico"; um de 120 horas, abordando temas transversais relacionados à cidadania; e um terceiro módulo, com duração de 360 horas, destinado à formação profissional, módulo no qual 60 horas são de aulas práticas.

20. A formação compreende atividades de formação escolar ( 800 horas), qualificação profissional (350 horas) e desenvolvimento de ação comunitária (50 horas), somando 1.200 horas presenciais. Atendendo às necessidades do público desse projeto, o currículo compreenderá, ainda, 400 horas de atividades não-presenciais.

Educ. Soc., Campinas, vol. 26, n. 92, p. 1087-1113, Especial - Out. 2005

Disponível em <http://www.cedes.unicamp.br> 
A política de educação profissional no Governo Lula...

21. Seminário Nacional pela Cidadania de Adolescentes - Adolescência, Escolaridade, Profissionalização e Renda. Propostas de Políticas Públicas para Adolescentes de Baixa escolaridade e Baixa renda. Brasília, setembro/2002 (mimeo.), 31p.

22. Decreto-lei n. 4.073, de 30 de janeiro de 1942.

\section{Referências bibliográficas}

BRASIL. Decreto no 2.208, de 17 de abril de 1997. Regulamenta o parágrafo $2^{\circ}$ do art. 36 e os art. 39 a 42 da Lei n. 9.394, de 20 de dezembro de 1996, que estabelece as diretrizes e bases da educação nacional. Diário Oficial da União, Brasília, DF, 18 abr. 1997. p. 7.760.

BRASIL. Decreto n. 5.154, de 23 de julho de 2004. Regulamenta o $\$$ $2^{\circ}$ do artigo 36 e os arts. 39 a 41 da Lei n. 9.394, de 20 de dezembro de 1996, que estabelece as diretrizes e bases da educação nacional, e dá outras providências. Diário Oficial da União, Brasília, DF, 24 jul. 2004 .

BRASIL. Decreto n. 5.478, de 24 de junho de 2005. Institui, no âmbito das instituições federais de educação tecnológica, o Programa de Integração da Educação Profissional ao Ensino Médio na Modalidade de Educação de Jovens e Adultos (PROEJA). Brasília, DF, 2005 b.

BRASIL. Medida provisória n. 238, de $1^{\circ}$ de fevereiro de 2005. Institui, no âmbito da Secretaria-Geral da Presidência da República, o Programa Nacional de Inclusão de Jovens (PRojovem), cria o Conselho Nacional de Juventude (CNJ) e cargos em comissão, e dá outras providências. Diário Oficial da União, Brasília, DF, 2 fev. 2005. p. 1.

BRASIL. Medida Provisória n. 251, de 14 de junho de 2005. Institui o Projeto Escola de Fábrica, autoriza a concessão de bolsas de permanência a estudantes beneficiários do Programa Universidade para Todos (PROUNI), institui o Programa de Educação Tutorial (РET), altera a Lei n. 5.537, de 21 de novembro de 1968, e a Consolidação das Leis do Trabalho (clt), e dá outras providências. Brasília, DF, 2005a. Disponível em: <http:// portal.mec.gov.br/setec/arquivos/pdf/medida_provisoria.pdf> Acesso em: 7 ago 2005.

BRASIL. CONSELHO NACIONAL DE EDUCAÇÃO (CNE). Resolução n. 3, de 26 de junho de 1998. Institui as Diretrizes Curriculares 
Nacionais para o Ensino Médio. Diário Oficial da República Federativa do Brasil, Brasília, DF, 5 ago. 1998a.

BRASIL. CONSELHO NACIONAL DE EDUCAÇÃO (CNE). Parecer n. 15, de 1 de junho de 1998. Diretrizes Curriculares Nacionais para o Ensino Médio. Brasília, DF, 1998b. Disponível em: <http:// www.mec.gov.br/cne/parecer.shtm>. Acesso em: 7 ago. 2005.

BRASIL. CONSELHO NACIONAL DE EDUCAÇÃO (CNE). Resolução n. 4, de 8 de dezembro de 1999. Institui as Diretrizes Curriculares Nacionais para a Educação Profissional de Nível Técnico. Brasília, DF, 1999a. Disponível em: <http://www.mec.gov.br/cne/resolução.shtm>. Acesso em: 8 ago. 2005.

BRASIL. CONSELHO NACIONAL DE EDUCAÇÃO (CNE). Parecer n. 16, de 5 de outubro de 1999. Diretrizes Curriculares Nacionais para a Educação Profissional de Nível Técnico. Brasília, DF, 1999b. Disponível em: <http://www.mec.gov.br/cne/parecer.shtm> Acesso em: 7 ago. 2005.

BRASIL. CONSELHO NACIONAL DE EDUCAÇÃO (CNE). Parecer n. 39, de 8 de dezembro de 2004. Aplicação do Decreto n. 5.154/2004 na Educação Profissional Técnica de nível médio e no Ensino Médio. Brasília, DF, 2004. Disponível em: <http://www.mec.gov/setec>. Acesso em: 7 ago. 2005

BRASIL. CONSELHO NACIONAL DE EDUCAÇÃO (CNE). Resolução n. 1, de 3 de março de 2005. Atualiza as Diretrizes Curriculares Nacionais Definidas pelo Conselho Nacional de Educação para o Ensino Médio e para a Educação Profissional Técnica de nível médio às disposições do Decreto n. 5.154/2004. Diário Oficial da República Federativa do Brasil, Brasília, DF, 11 mar. 2005.

BRASIL. MINISTERIO DA EDUCAÇÃO. Orientaçôes curriculares do ensino médio. Brasília, DF, 2004.

BRASIL. MINISTERIO DA EDUCAÇÃO. SECRETARIA DE EDUCAÇÃO PROFISSIONAL E TECNOLOGICA. Subsidios para o processo de discussão da proposta de anteprojeto de lei da educação profissional e tecnológica. Disponível em: <http://www.mec.gov/setec>. Acesso em: 2 fev. 2005. 
A política de educação profissional no Governo Lula...

CIAVATTA, M. Formação integrada: a escola e o trabalho como lugares de memória e identidade. In: Frigotto, G.; Ciavatta, M.; Ramos, M. (Org.). Ensino médio integrado: concepção e contradições. São Paulo: Cortez, 2005. p. 83-105.

CORDEIRO, P. A reforma da educação profissional dos anos 90 no Centro Federal de Educação Tecnológica de Pernambuco (CEFETPE) - 1998 a 2003. 2004. 304f. Dissertação (Mestrado) - Faculdade de Educação, Universidade Federal de Pernambuco, Recife.

COSTA, H.; CONCEIÇÃO, M. (Org.). Educação integral e sistema de reconhecimento e certificação educacional e profissional. São Paulo: CUT, 2005.

FERREIRA, E.; GARCIA, S. O ensino médio integrado à educação profissional: um projeto em construção nos estados do Espírito Santo e do Paraná. In: Frigotto, G.; CiavatTa, M.; Ramos, M. (Org.). Ensino médio integrado: concepção e contradições. São Paulo: Cortez, 2005. p. 148-174.

FRIGOTTO, G. Juventude, trabalho e educação no Brasil: perplexidades, desafios e perspectivas. In: Novaes, R.; Vannuchi, P. Juventude e sociedade: trabalho, educação, cultura e participação. São Paulo: Fundação Perseu Abramo, 2004. p. 180-216.

FRIGOTTO, G. Concepções e mudanças no mundo do trabalho e o ensino médio. In: Frigotto, G.; Ciavatta, M.; Ramos, M. (Org.). Ensino médio integrado: concepção e contradições. São Paulo: Cortez, 2005. p. 57-82.

FRIGOTTO, G.; CIAVATTA, M. A formação do "cidadão produtivo": da política de expansão do ensino médio técnico nos anos 80 à fragmentação da educação profissional nos anos 90: entre discursos e imagens (2001-2004). Rio de Janeiro: UfF, 2004. Relatório de pesquisa.

FRIGOTTO, G., CIAVATTA, M.; RAMOS, M. O trabalho como princípio educativo no projeto de educação integral de trabalhadores. In: CosTA, H.; CONCEIÇÃO, M. (Org.). Educação integral e sistema de reconhecimento e certificação educacional e profissional. São Paulo: CuT, 2005a. p. 19-62.

FRIGOTTO, G., CIAVATTA, M.; RAMOS, M. A gênese do Decreto n. 5.154/2004: um debate no contexto controverso da democracia restrita. In: Frigotto, G.; Ciavatta, M.; Ramos, M. (Org.). Ensino médio integrado: concepção e contradições. São Paulo: Cortez, 2005b, p. 21-56. 
KUENZER, A. As propostas de decreto para regulamentação do ensino médio $e$ da educação profissional: uma análise crítica. Curitiba, 2003. (mimeo.). Disponível em: <www.anped.org.br/representacoesanped2004.pdf> Acesso: 2005

LAFLAMME, C.; BABY, A. Integration of youth into labor market: some theoretical consideration on a structural-conjectural issue. The Alberta Journal of Education Research, Alberta, v. 39, n. 1, 1993.

MONTAÑO, C. Terceiro setor e questão social: crítica ao padrão emergente de intervenção social. São Paulo: Cortez, 2002.

POCHMANN, M. Juventude em busca de novos caminhos no Brasil. In: Novaes, R.; VANnUCHI, P. Juventude e sociedade: trabalho, educação, cultura e participação. São Paulo: Fundação Perseu Abramo, 2004. p. 217-241.

RAMOS, M. Possibilidades e desafios na organização do currículo integrado. In: Frigotto, G.; Ciavatta, M.; Ramos, M. (Org.). Ensino médio integrado: concepção e contradiçôes. São Paulo: Cortez, 2005. p. 106-127.

RODRIGUES, J. Quarenta anos adiante: breves anotações a respeito do novo decreto de Educação Profissional. Trabalho Necessário, Rio de Janeiro, v. 3, n. 3, 2005. Disponível em: <http://www.uff.br/trabalhonecessario>. Acesso em: 7 ago. 2005.

ROMANELLI, O. História da educação no Brasil. 19. ed. Rio de Janeiro: Vozes, 1997.

SAVIANI, D. O choque teórico da politecnia: trabalho, educação e saúde. Revista da EPSJV/FIOCRUZ, Rio de Janeiro, n. 1, p. 131-52, 2003.

TOMMASI, L.; WARDE, M.; HADDAD, S. O Banco Mundial e as politicas educacionais. São Paulo: Cortez, 1996. 